\title{
Excited-State Dynamics of the Thiopurine Prodrug 6-Thioguanine: Can N9-Glycosylation Affect Its Phototoxic Activity?
}

\author{
Brennan Ashwood ${ }^{1}$, Steffen Jockusch ${ }^{2}$ and Carlos E. Crespo-Hernández ${ }^{1, *}$ \\ 1 Department of Chemistry and Center of Chemical Dynamics, Case Western Reserve University, \\ Cleveland, OH 44106, USA; bga11@case.edu \\ 2 Department of Chemistry, Columbia University, New York, NY 10027, USA; sj67@columbia.edu \\ * Correspondence: carlos.crespo@case.edu; Tel.: +1-216-368-1911
}

Academic Editor: Derek J. McPhee

Received: 17 January 2017; Accepted: 24 February 2017; Published: 28 February 2017

\begin{abstract}
Thioguanine, an immunosuppressant and anticancer prodrug, has been shown to induce DNA damage and cell death following exposure to UVA radiation. Its metabolite, 6-thioguanosine, plays a major role in the prodrug's overall photoreactivity. However, 6-thioguanine itself has proven to be cytotoxic following UVA irradiation, warranting further investigation into its excited-state dynamics. In this contribution, the excited-state dynamics and photochemical properties of 6-thioguanine are studied in aqueous solution following UVA excitation at $345 \mathrm{~nm}$ in order to provide mechanistic insight regarding its photochemical reactivity and to scrutinize whether N9-glycosylation modulates its phototoxicity in solution. The experimental results are complemented with time-dependent density functional calculations that include solvent dielectric effects by means of a reaction-field solvation model. UVA excitation results in the initial population of the $S_{2}\left(\pi \pi^{*}\right)$ state, which is followed by ultrafast internal conversion to the $S_{1}\left(n \pi^{*}\right)$ state and then intersystem crossing to the triplet manifold within $560 \pm 60 \mathrm{fs}$. A small fraction (ca. $25 \%$ ) of the population that reaches the $S_{1}\left(n \pi^{*}\right)$ state repopulates the ground state. The $T_{1}\left(\pi \pi^{*}\right)$ state decays to the ground state in $1.4 \pm 0.2 \mu \mathrm{s}$ under $\mathrm{N}_{2}$-purged conditions, using a $0.2 \mathrm{mM}$ concentration of 6-thioguanine, or it can sensitize singlet oxygen in $0.21 \pm 0.02$ and $0.23 \pm 0.02$ yields in air- and $\mathrm{O}_{2}$-saturated solution, respectively. This demonstrates the efficacy of 6-thioguanine to act as a Type II photosensitizer. N9-glycosylation increases the rate of intersystem crossing from the singlet to triplet manifold, as well as from the $T_{1}\left(\pi \pi^{*}\right)$ state to the ground state, which lead to a ca. $40 \%$ decrease in the singlet oxygen yield under air-saturated conditions. Enhanced vibronic coupling between the singlet and triplet manifolds due to a higher density of vibrational states is proposed to be responsible for the observed increase in the rates of intersystem crossing in 6-thioguanine upon N9-glycosylation.
\end{abstract}

Keywords: sulfur-substituted DNA bases; prodrugs; phototoxicity; excited-state dynamics; singlet oxygen generation; glycosylation; low-temperature emission; transient absorption; TD-DFT

\section{Introduction}

Sulfur-substituted purine nucleobases have long been prescribed to treat inflammatory bowel disease, arthritis, and various cancers [1-6]. Each act as a prodrug, in which their active form is produced following cellular metabolization. It has been shown that prolonged treatment of patients with these thiopurines is associated with a 10-fold and 65- to 250-fold increase in basal and squamous cell carcinomas, respectively $[3,5]$. The drastic increase in skin cancers is thought to result primarily from the metabolization of the thiopurine prodrugs into cellular DNA followed by photosensitized damage upon UVA absorption. 
6-Thioguanosine (6tGuo) is produced and incorporated into DNA following extensive metabolization of 6-thioguanine (6tGua), 6-mercaptopurine, or azathiopurine [7-11]. 6tGuo has been shown to induce DNA damage and cell death upon exposure to UVA radiation, which is correlated to the significant increase in skin cancers following prolonged treatment with thiopurine prodrugs [9,11-18]. It is thought that 6tGuo may photosensitize cells through a Type II mechanism due to its relatively high singlet oxygen $\left({ }^{1} \mathrm{O}_{2}\right)$ yield of ca. $25 \%$ [19] and more efficient light absorption compared to that for the canonical base guanine in aqueous solution $[19,20]$. This hypothesis is supported by the observation of $\mathrm{O}_{2}$-dependent generation of the photoproducts guanine-6-sulfinate and guanine-6-sulfonate $[13,15,21,22]$. However, other studies indicate that 6 tGuo also reacts directly with biological substrates, forming DNA intra- and inter-strand crosslinks and DNA-protein crosslinks [17,23-25]. The precursor and main chromophore of 6tGuo, 6tGua (see Figure 1), is also known to induce significant cell death following UVA irradiation [11], showing that 6tGua itself contributes to the overall photocytotoxic activity of the prodrug. Complete elucidation of the underlying photophysics of 6tGua and 6tGuo is required in order to understand their phototoxicity in cellular environments. Recently, 6tGuo was shown to undergo ultrafast intersystem crossing (ISC) following UVA excitation to populate a long-lived triplet state [26], which has been proposed to be responsible for direct reactions with biological substrates, as well as the production of reactive oxygen species (ROS) [17,19,23-25].

While the only structural difference between 6tGua and 6tGuo is N9-glycosidic substitution (Figure 1), recent work has shown that the sugar substituent can play a significant role in the excited-state properties of sulfur-substituted DNA bases $[27,28]$. Taras-Goślińska et al. showed that N1-glycosylation of the thiopyrimidine 2-thiothymine reduces the lifetime of the lowest-energy triplet state, which potentially reduces its reactivity towards DNA [27]. Additionally, Pollum et al. found that 2-thiothymidine undergoes intersystem crossing (ISC) more rapidly than 2-thiothymine [28], but it has yet to be shown whether similar changes occur in the thiopurine prodrugs upon N9-glycosylation. In particular, the role that glycosylation has on the photochemistry and phototoxicity of 6tGua is of great relevance due to its wide clinical applications and the reported increased incidence of skin cancer among patients with prolonged treatment $[3,5]$. In order to fill this knowledge gap, we have investigated the excited-state dynamics of $6 \mathrm{tGua}$ from femtoseconds to microsecond in aqueous solution, its reactivity toward molecular oxygen, and compared the results with those performed previously for $6 \mathrm{tGuo}$ under identical conditions. In addition, the time-dependent implementation of density functional theory (TD-DFT) is used to compute vertical excitation energies for 6tGua in aqueous environment and the results are compared to those previously reported for 6tGuo under equal conditions.

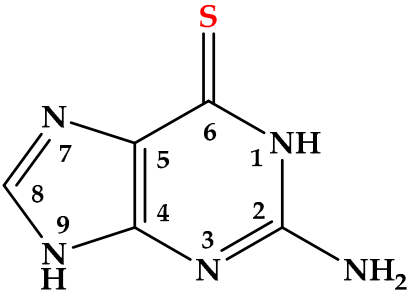

6-Thioguanine (6tGua)

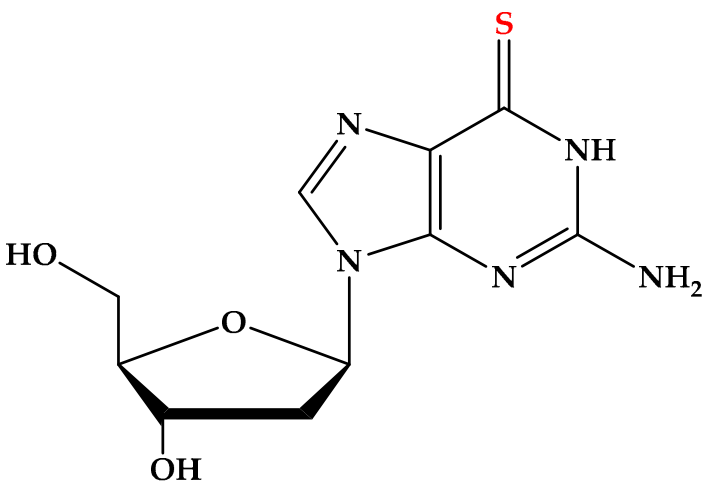

6-Thio-2'-deoxyguanosine (6tGuo)

Figure 1. Molecular structures and common ring numbering of the nucleobase chromophore. 


\section{Results and Discussion}

\subsection{Steady-State Absorption of $6 t G u a$}

Figure 2 shows the ground-state absorptivity spectra of 6tGua and 6tGuo in phosphate buffer saline (PBS) solution at pH 7.4. The lowest-energy absorption band of 6tGua has a maximum at $341 \mathrm{~nm}\left(18,000 \mathrm{M}^{-1} \mathrm{~cm}^{-1}\right)$. UVC maxima are observed at $254 \mathrm{~nm}\left(6000 \mathrm{M}^{-1} \mathrm{~cm}^{-1}\right)$ and $204 \mathrm{~nm}$ $\left(19,200 \mathrm{M}^{-1} \mathrm{~cm}^{-1}\right)$ with a shoulder at $220 \mathrm{~nm}\left(13,500 \mathrm{M}^{-1} \mathrm{~cm}^{-1}\right)$. 6tGuo has a very similar ground-state absorption spectrum, showing maxima at $341 \mathrm{~nm}\left(23,000 \mathrm{M}^{-1} \mathrm{~cm}^{-1}\right), 258 \mathrm{~nm}\left(7700 \mathrm{M}^{-1} \mathrm{~cm}^{-1}\right)$, and $208 \mathrm{~nm}\left(21,100 \mathrm{M}^{-1} \mathrm{~cm}^{-1}\right)$ with a shoulder at $227 \mathrm{~nm}\left(12,000 \mathrm{M}^{-1} \mathrm{~cm}^{-1}\right)$. N9-glycosylation increases the absorptivity coefficients of both the UVC and UVA absorption bands.
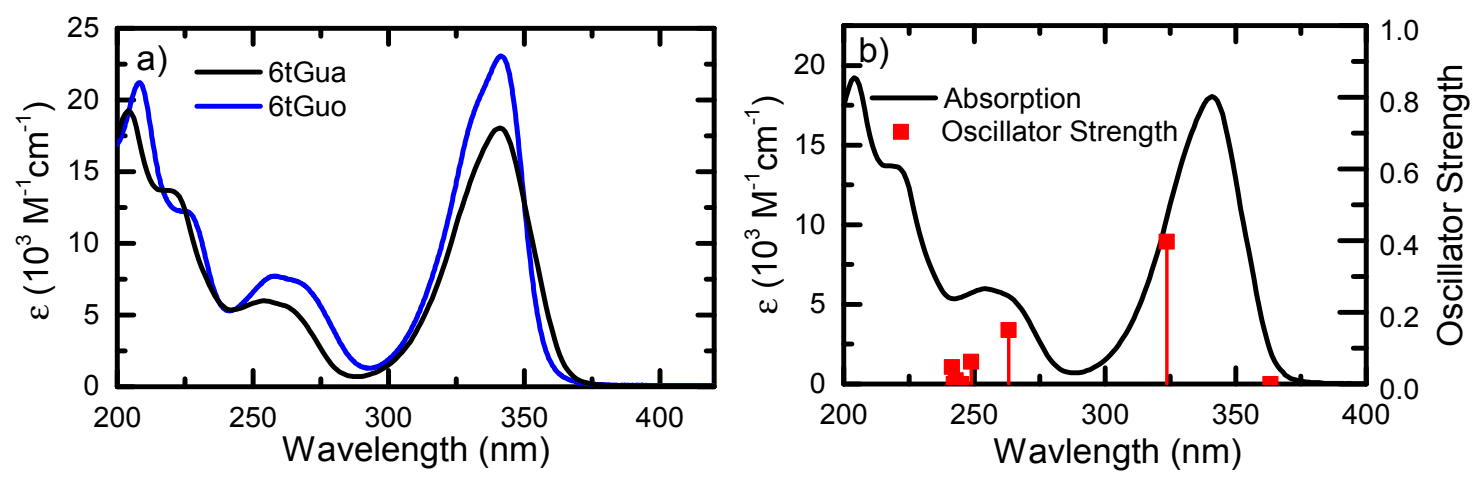

Figure 2. (a) Ground-state absorptivity of 6tGua and 6tGuo in PBS pH 7.4; (b) Ground-state absorptivity spectrum of 6tGua in PBS plotted with oscillator strengths calculated at the TD-PBE0/IEFPCM/6-311++G(d,p) level of theory. Vertical excitation energies were redshifted by $0.15 \mathrm{eV}$ relative to those reported in Table 1 to better match the experimental absorptivity spectrum.

\subsection{Steady-State and Time-Resolved Emission of $6 t G u a$}

At room temperature, 6tGua shows only weak luminescence that is dominated by fluorescence from the photoproduct guanine-6-sulfonate (see Supporting Information) [29]. In a frozen matrix of Tris buffer $\mathrm{pH} 7.4$ at $77 \mathrm{~K}$, luminescence from 6tGua was observed. Under steady-state conditions following $340 \mathrm{~nm}$ excitation, a strong emission band is observed from $430 \mathrm{~nm}$ to $550 \mathrm{~nm}$, showing a maximum at $468 \mathrm{~nm}$ and shoulders at $437 \mathrm{~nm}$ and $494 \mathrm{~nm}$. A weaker emission band is also observed from $350 \mathrm{~nm}$ to $400 \mathrm{~nm}$, exhibiting maxima at $362 \mathrm{~nm}$ and $377 \mathrm{~nm}$. When using pulsed $340 \mathrm{~nm}$ excitation and time-gated detection (10-30 ms), only the luminescence band from $430 \mathrm{~nm}$ to $550 \mathrm{~nm}$ is observed (Figure 3a), which decays with a lifetime of $45 \mathrm{~ms}$ (Figure 3b). Due to its long lifetime, significant redshift of $62 \mathrm{~nm}\left(3780 \mathrm{~cm}^{-1}\right)$ from the lowest-energy absorption $\left(\lambda_{\max }\right)$, and quenching by molecular oxygen at room temperature (Figure S2), the emission band from $430 \mathrm{~nm}$ to $550 \mathrm{~nm}$ is assigned to phosphorescence emission from the lowest-energy triplet state to the ground state of 6tGua. This assignment is in agreement with previous emission spectra of 6tGua [30-33], specifically those reported at $\mathrm{pH}>7$ [30], and has been observed in several thionyl-containing aromatic compounds [34-38]. A triplet energy of $2.84 \mathrm{eV}$ was determined from the highest-energy maximum of the emission band (437 $\mathrm{nm})$, which is close in energy with vertical $(2.73 \mathrm{eV})$ and adiabatic $(3.04 \mathrm{eV})$ $\mathrm{T}_{1}$ state energy computed from TD-DFT calculations (see below). While a lifetime of $45 \mathrm{~ms}$ may be short for phosphorescence from a $\pi \pi^{*}$ state in aromatic carbonyl compounds [39,40], the enhanced spin-orbit coupling following sulfur-substitution is expected to reduce the magnitude of the lifetime of phosphorescence, as observed previously for other sulfur-substituted DNA bases [41,42]. The weaker luminescence band from $350 \mathrm{~nm}$ to $400 \mathrm{~nm}$ overlaps the ground-state absorption and decays within the time resolution of the time-gated detection, suggesting that it is due to fluorescence emission from 6tGua. 

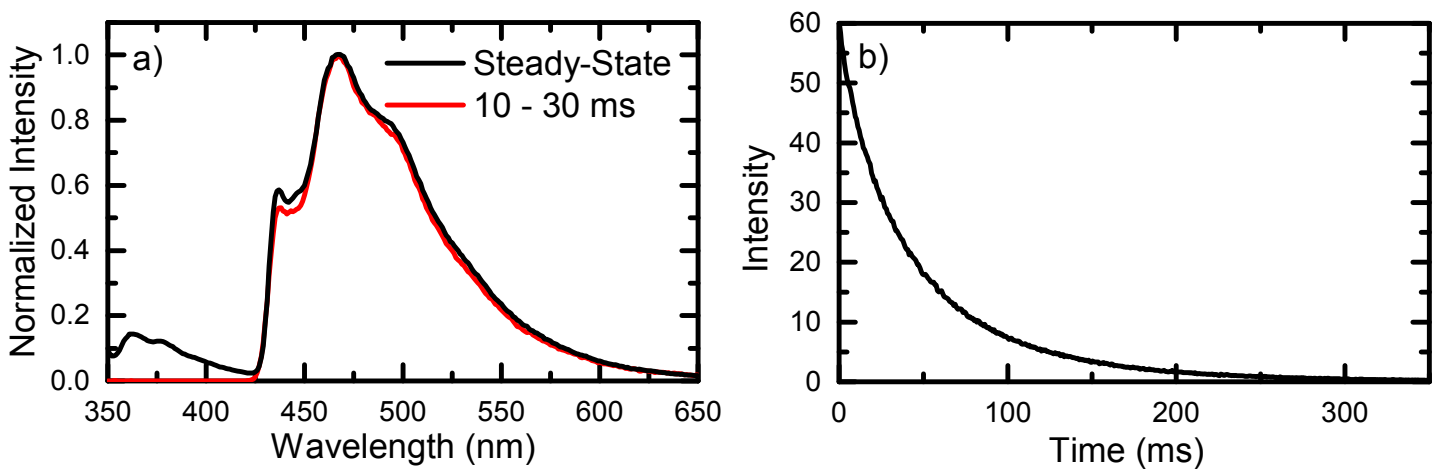

Figure 3. (a) Emission spectra of $6 \mathrm{tGua}$ in Tris buffer $\mathrm{pH} 7.4$ in frozen matrix at $77 \mathrm{~K}$ following steady-state (black) and pulsed (red) excitation at $340 \mathrm{~nm}$. The time-resolved spectrum was recorded 10-30 ms following pulsed excitation; (b) Representative phosphorescence decay trace of 6tGua monitored at $480 \mathrm{~nm}$ following pulsed excitation at $340 \mathrm{~nm}$ in frozen matrix at $77 \mathrm{~K}$.

\subsection{Quantum-Chemical Calculations of $6 t G u a$}

Ground-state optimizations of $6 \mathrm{tGua}$ were performed in vacuum and in water environments at the PBE0/IEFPCM/6-311++G(d,p) level of theory. Vertical excitation energy calculations were performed subsequently on the optimized geometry in the corresponding solvent environment. A reaction field was used to model the solvation effects from water. We note, however, that it has been shown recently that explicit solvent effects are needed to most accurately describe the excitation energies in DNA bases and their thio-derivatives [43-45]. The calculations shown in Table 1, and in Figures 2 and 4, indicate that a minimum of five excited-states must be considered, at the TD-DFT level of theory, to explain the relaxation mechanism of $6 \mathrm{tGua}$ following excitation with UVA radiation at $345 \mathrm{~nm}$. Particularly, upon excitation, the $S_{2}\left(\pi \pi^{*}\right)$ state is expected to be populated overwhelmingly (Figure 2) due to its relatively high oscillator strength. Vertical excitations were calculated previously for $6 \mathrm{tGua}$ using multi-state second-order perturbation theory on state-average complete active space self-consistent-field wavefunctions (MS-CASPT2//SA-CASSCF) with the ANO-L basis set [46]. The singlet energies computed at this level of theory resemble those from TD-DFT, but the triplet energies are generally much higher in energy (Table 1). This is consistent with the observation that TD-DFT usually underestimate the energies of low-lying triplet states of molecules containing large aromatic systems $[47,48]$.

Table 1. Vertical excitation energies for $6 \mathrm{tGua}$ in vacuum and in water environments, and for $6 \mathrm{tGuo}$ in water [26], computed at the TD-PBE0/IEFPCM/6-311++G(d,p) level of theory. Oscillator strengths are provided in parentheses. Vertical excitation energies computed at the MS-CASPT2//CASSCF(14,12)/ANO-L level of theory [46] are also given for comparison.

\begin{tabular}{ccccc}
\hline State & Vacuum $(\mathbf{e V})$ & Vacuum $(\mathbf{e V})[46]$ & Water $(\mathbf{e V})$ & 6tGuo Water $(\mathbf{e V})[26]$ \\
\hline $\mathrm{S}_{2}\left(\pi \pi^{*}\right)$ & $4.14(0.26)$ & $4.05(0.54)$ & $4.00(0.40)$ & $3.96(0.45)$ \\
$\mathrm{S}_{1}\left(\mathrm{n} \pi^{*}\right)$ & $3.25(0.00)$ & $3.36(0.00)$ & $3.58(0.00)$ & $3.64(0.00)$ \\
$\mathrm{T}_{3}\left(\pi \pi^{*}\right)^{\mathrm{a}}$ & 3.62 & 4.24 & 3.92 & 3.88 \\
$\mathrm{~T}_{2}\left(\mathrm{n} \pi^{*}\right)$ & 2.92 & 3.31 & 3.34 & 3.42 \\
$\mathrm{~T}_{1}\left(\pi \pi^{*}\right)$ & 2.61 & 3.10 & 2.73 & 2.74 \\
$\Delta \mathrm{E}\left(\mathrm{S}_{2}-\mathrm{S}_{1}\right)$ & 0.89 & 0.69 & 0.42 & 0.32 \\
$\Delta \mathrm{E}\left(\mathrm{S}_{2}-\mathrm{T}_{3}\right)$ & 0.52 & -0.19 & 0.08 & 0.08 \\
$\Delta \mathrm{E}\left(\mathrm{S}_{2}-\mathrm{T}_{2}\right)$ & 1.22 & 0.74 & 0.66 & 0.54 \\
$\Delta \mathrm{E}\left(\mathrm{S}_{1}-\mathrm{T}_{2}\right)$ & 0.33 & 0.05 & 0.24 & 0.22 \\
$\Delta \mathrm{E}\left(\mathrm{S}_{1}-\mathrm{T}_{1}\right)$ & 0.64 & 0.26 & 0.85 & 0.90 \\
\hline
\end{tabular}

a The $\mathrm{T}_{3}$ state of $6 \mathrm{tGuo}$ was previously reported as having primarily $\mathrm{n} \pi^{*}$ character in [26]. Re-examination of the vertical excitation energies calculations for $6 t$ tGuo in water reveals instead that the $T_{3}$ state has mostly $\pi \pi^{*}$ character. 


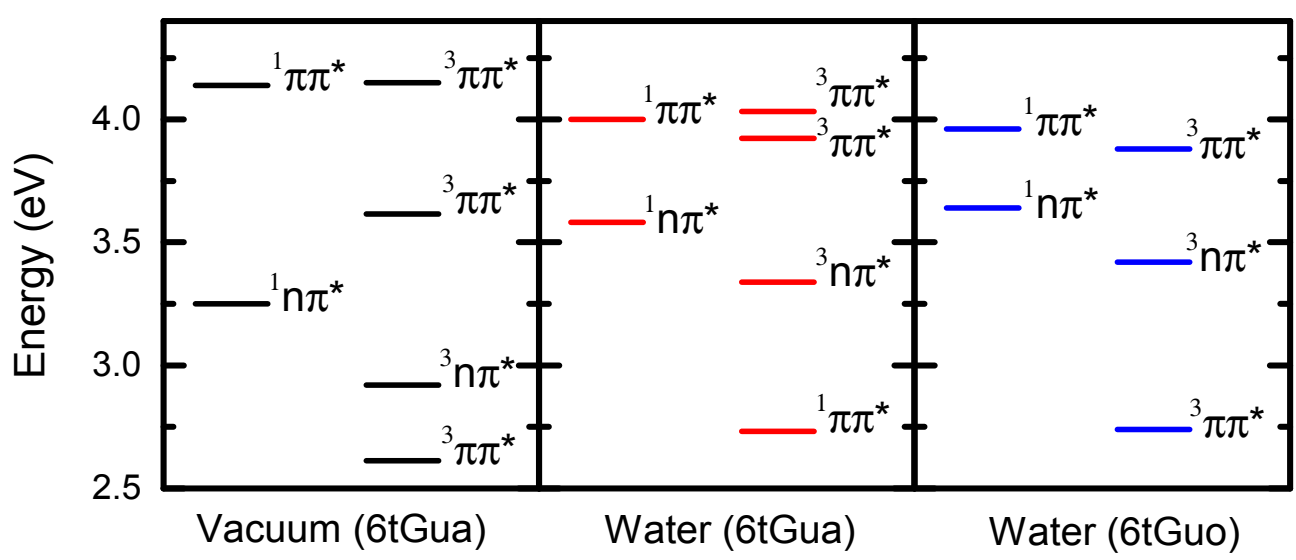

Figure 4. Vertical excitation energies for 6tGua in vacuum and in water environments, and for 6tGuo in water, calculated at the TD-PBE0/IEFPCM/6-311++G(d,p) level of theory. 6tGuo values were reported previously [26].

The observation of phosphorescence, and the lack of fluorescence from 6tGua (Figure 2), suggest that a significant portion of the excited-state population undergoes intersystem crossing (ISC) to the triplet manifold, as previously reported for other sulfur-substituted DNA bases $[19,26,28,34,49,50]$. According to the TD-DFT calculations, intersystem crossing from either the $S_{2}\left(\pi \pi^{*}\right)$ state to $T_{2}\left(n \pi^{*}\right)$ state, or from the $S_{1}\left(n \pi^{*}\right)$ state to $T_{1}\left(\pi \pi^{*}\right)$ state, is favorable, as the change in state character is in agreement with the El-Sayed propensity rules (Figure 4) [51]. These pathways are in agreement with those predicted from previous vertical excitation energies computed for 6tGua at the MS-CASPT2/ /CASSCF $(14,12) /$ ANO-L level of theory in vacuum [46].

The TD-DFT calculations performed in this work can be compared directly with those computed previously for the anti-sugar conformation of 6 tGuo at the TD-PBE0/IEFPCM/6-311++G(d,p) level of theory [26]. As depicted in Figure 4 , the $S_{2}\left(\pi \pi^{*}\right), S_{1}\left(n \pi^{*}\right), T_{3}\left(\pi \pi^{*}\right), T_{2}\left(n \pi^{*}\right)$, and $T_{1}\left(\pi \pi^{*}\right)$ vertical excitation energies of $6 \mathrm{tGua}$ are all within $0.1 \mathrm{eV}$ of those computed for $6 \mathrm{tGuo}$. This similarity leads to nearly identical energy gaps between the $S_{2}\left(\pi \pi^{*}\right)$ and $T_{3}\left(\pi \pi^{*}\right), S_{2}\left(\pi \pi^{*}\right)$ and $S_{1}\left(n \pi^{*}\right), S_{2}\left(\pi \pi^{*}\right)$ and $\mathrm{T}_{2}\left(\mathrm{n} \pi^{*}\right)$, and the $\mathrm{S}_{1}\left(\mathrm{n} \pi^{*}\right)$ and $\mathrm{T}_{1}\left(\pi \pi^{*}\right)$ states.

\subsection{Transient Absorption Spectroscopy of $6 t \mathrm{Gua}$}

Figure 5 shows the transient absorption spectra of $6 \mathrm{tGua}$ in PBS from sub-picosecond to a time delay of $100 \mathrm{ps}$. UVA excitation results in the formation of bands centered at $375 \mathrm{~nm}$ and $520 \mathrm{~nm}$, as well as a negative-amplitude absorption band at wavelengths shorter than $\sim 360 \mathrm{~nm}$. This absorption band overlaps the ground-state absorption (Figure 2), and thus is assigned to ground-state depopulation. Ground-state depopulation is followed by a slight decay and rise of the $520 \mathrm{~nm}$ and $375 \mathrm{~nm}$ maxima, respectively, which is observed within 100 ps. During this process, the negative-amplitude absorption band significantly decreases in magnitude (Figure $5 b$ ). The resulting transient absorption spectrum remains unchanged through the full 3 ns time-delay available with our delay stage, indicating that the majority of excited-state population decays on nanosecond to microsecond timescales.

The femtosecond transient absorption kinetics of $6 \mathrm{tGua}$ were globally fitted to a two-lifetime exponential model (Figure 5b). Similar lifetimes (within the error) were obtained using a two-component sequential model. Decay-associated spectra generated through global analysis using a sequential model are shown in Figure $5 \mathrm{~d}$, and match nicely with the experimental transient absorption spectra. 

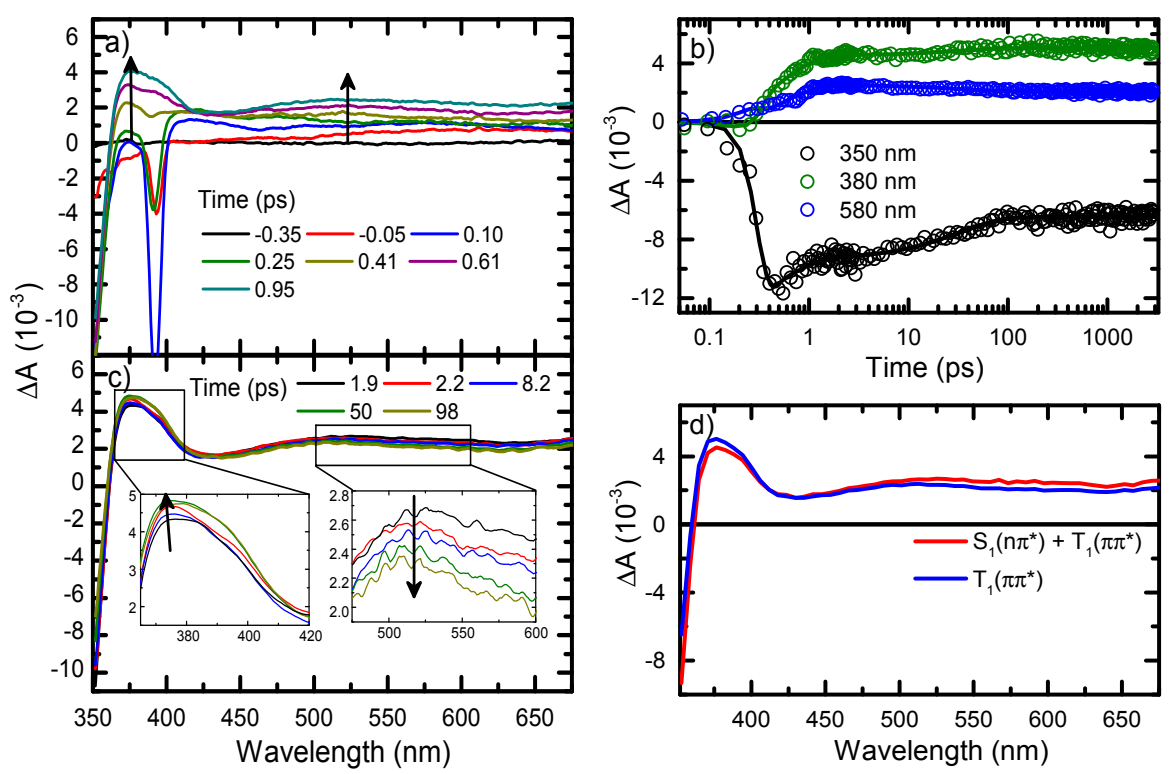

Figure 5. Transient absorption spectra of 6tGua in PBS from (a) sub-picosecond to (c) picosecond time-delays following $345 \mathrm{~nm}$ excitation. The negative signals from ca. $380 \mathrm{~nm}$ to $400 \mathrm{~nm}$ (a) are due to stimulated Raman emissions from the solvent, and are observed within the cross correlation of the pump and probe beams; (b) Representative kinetic decay traces of 6tGua in PBS out to 3 ns at indicated probe wavelengths; (d) Decay-associated spectra of 6tGua in PBS generated from global analysis using a sequential model.

The full excited-state decay of 6tGua was monitored using nanosecond transient absorption spectroscopy ( $\sim 400$ ps instrument response function) in air and in deaerated solution (Figure 6). The time-domain transient absorption data was fitted successfully to a single-lifetime exponential model, producing the lifetimes shown in Table 2. The long-lived nature of this excited-state species further supports its assignment to the lowest-energy triplet state. The decay of the $T_{1}$ state is significantly quenched in the presence of molecular oxygen (Figure 6), suggesting that it may undergo reactions to produce reactive oxygen species, as observed recently for 6tGuo [19].

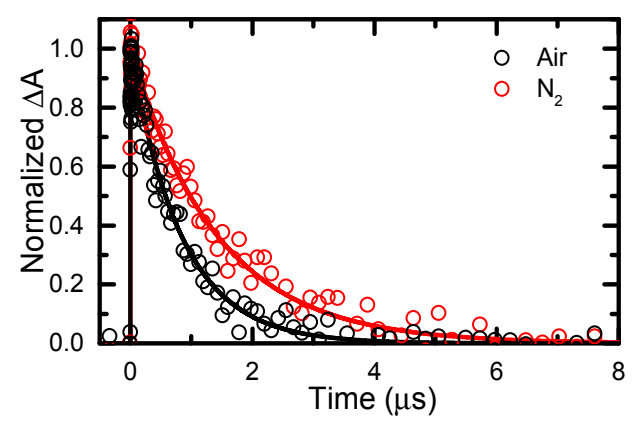

Figure 6. Representative decay-traces for 6tGua triplet absorption monitored at $350 \mathrm{~nm}$ in PBS under air- and $\mathrm{N}_{2}$-saturated conditions following $345 \mathrm{~nm}$ excitation. Traces were fitted to a single-lifetime exponential kinetic model.

Time-resolved luminescence spectroscopy was employed to quantify singlet oxygen generation from 6tGua following UVA excitation in air- and in $\mathrm{O}_{2}$-saturated aqueous solution (Figure 7). As reported in Table 2, the ${ }^{1} \mathrm{O}_{2}$ quantum yields are much larger than for the canonical base guanine [20], and are nearly identical in air- and in $\mathrm{O}_{2}$-saturated conditions. This is likely due to the relatively long triplet decay lifetime of $6 \mathrm{tGua}$. Previously, Gao et al. measured a ${ }^{1} \mathrm{O}_{2}$ quantum yield of $0.56 \pm 0.18$ 
for 6tGua following UVA excitation in $\mathrm{O}_{2}$-saturated $\mathrm{pH} 7.4$ Tris buffer [9]. As recently discussed in detail for 6tGuo [19], this >2-fold increase compared to the value reported herein is likely a result of an empirical correction factor of 2 applied toward their quantum yield in an attempt to account for oxidation of $6 \mathrm{tGua}$ that was observed in their experiments [9]. However, the ${ }^{1} \mathrm{O}_{2}$ yield determined by Gao et al. is within error of that reported in this work if this correction factor is not included.

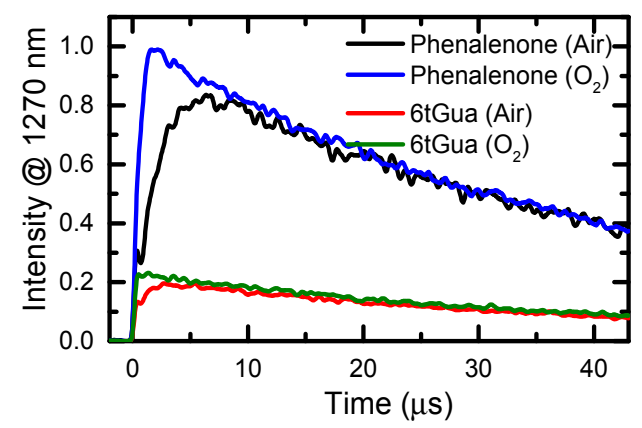

Figure 7. ${ }^{1} \mathrm{O}_{2}$ phosphorescence signal measured at $1270 \mathrm{~nm}$ from air- and $\mathrm{O}_{2}$-saturated solutions of 6tGua and the standard phenalenone $\left(\Phi_{\Delta}=0.98\right)$ [52] in Tris buffer at $\mathrm{pH} 7.4$ following pulsed excitation at $355 \mathrm{~nm}(7 \mathrm{~ns}$ pulse width).

Table 2. Lifetimes of 6tGua extracted from global fitting of transient absorption data. Also included are those reported for 6tGuo in PBS pH $7.4[19,26]$.

\begin{tabular}{lllllll}
\hline Base & $\boldsymbol{\tau}_{\mathbf{1}}$ (ps) & $\boldsymbol{\tau}_{\mathbf{2}}$ (ps) & $\boldsymbol{\tau}_{\mathbf{3}}$ (ns) (Air) & $\boldsymbol{\tau}_{\mathbf{3}} \mathbf{( n s )}\left(\mathbf{N}_{\mathbf{2}}\right)$ & $\boldsymbol{\Phi}_{\boldsymbol{\Delta}}$ (Air) & $\boldsymbol{\Phi}_{\boldsymbol{\Delta}}\left(\mathbf{O}_{\mathbf{2}}\right)$ \\
\hline 6tGua & $0.56 \pm 0.06$ & $26 \pm 3$ & $830 \pm 70$ & $1420 \pm 180$ & $0.21 \pm 0.02$ & $0.23 \pm 0.02$ \\
6tGuo & $0.31 \pm 0.05[26]$ & $80 \pm 15[26]$ & $460 \pm 15[26]$ & $720 \pm 10[26]$ & $0.13 \pm 0.02[19]$ & $0.24 \pm 0.02[19]$ \\
\hline
\end{tabular}

\subsection{Excited-State Relaxation Mechanism of $6 t G u a$}

The first lifetime $\left(\tau_{1}\right)$ in the transient absorption data of $6 \mathrm{tGua}$ corresponds to the rise of the maxima at $375 \mathrm{~nm}$ and $520 \mathrm{~nm}$, while the second $\left(\tau_{2}\right)$ corresponds to the decay and rise of the $520 \mathrm{~nm}$ and $375 \mathrm{~nm}$ bands, respectively. In addition, the negative signal at ca. $350 \mathrm{~nm}$ appears to repopulate slightly during $\tau_{1}$, but this may result from an increase in excited-state absorption on top of the depopulated region. The most negative ground-state depopulation amplitude (-12 mOD) occurs at a $410 \mathrm{fs}$ time delay (Figure 5), at which point the $375 \mathrm{~nm}$ maximum is at an amplitude of $2 \mathrm{mOD}$. During $\tau_{1}$, both the depopulation band $(\sim 350 \mathrm{~nm})$ and maximum at $375 \mathrm{~nm}$ increase by $\sim 2 \mathrm{mOD}$, suggesting that the apparent ground-state repopulation in Figure 6 originates from a rise in excited-state absorption. Therefore, we assign $\tau_{1}$ to ultrafast population of the triplet manifold in $6 \mathrm{tGua}$, a process that has been reported for $6 \mathrm{tGuo}$ and many other sulfur-substituted DNA derivatives [26-28,34,50,53-55]. This is further supported by the enhanced spin-orbit between the singlet and triplet manifolds expected upon conjugation of the sulfur atom, which has been reported for several thiobases [45,46,49,55-59]. Under the assumption that the transient absorption cross sections for 6tGua in PBS aqueous solution are similar to those reported previously for 6tGuo [26], and that the experimental conditions were similar, a $(\geq 60 \pm 20) \%$ ISC yield can be estimated for $6 \mathrm{tGua}$. However, we remark that this is simply a crude lower-limit estimation, which is within errors of the reported triplet yield for 6tGuo [26].

As discussed above, TD-DFT vertical excitation energies (Table 1 and Figure 3) indicate that intersystem crossing from the $S_{2}\left(\pi \pi^{*}\right)$ state to the $T_{2}\left(n \pi^{*}\right)$ state, or from the $S_{1}\left(n \pi^{*}\right)$ state to the $\mathrm{T}_{1}\left(\pi \pi^{*}\right)$ state, should be most favorable, as they both obey the El-Sayed propensity rules [51]. These predictions agree with vertical excitation energy calculations performed at the MS-CASPT2/ /CASSCF(14,12)/ANO-L level of theory [46]. However, MS-CASPT2/ /SA-CASSCF calculations were also performed to determine the singlet/singlet and singlet/triplet crossing points 
and state minima $[46,58]$. These computations indicate that a $S_{2}\left(\pi \pi^{*}\right) / S_{1}\left(n \pi^{*}\right)$ conical intersection is accessible barrierlessly from the Frank-Condon (FC) region of the $S_{2}\left(\pi \pi^{*}\right)$ state potential energy surface (PES), suggesting that internal conversion from the $S_{2}\left(\pi \pi^{*}\right)$ state to the $S_{1}\left(n \pi^{*}\right)$ state occurs rapidly ( $10 \mathrm{fs})$. The triplet manifold is populated subsequently, primarily through the dark $\mathrm{S}_{1}\left(\mathrm{n} \pi^{*}\right)$ state, as has be shown for other sulfur-substituted and canonical DNA bases $[46,49,59]$. The $S_{1}$ PES exhibits both $\pi \pi^{*}$ and $n \pi^{*}$ minima with energies of $3.78 \mathrm{eV}$ and $3.18 \mathrm{eV}$, respectively, while the $\mathrm{T}_{1}$ state PES has two $\pi \pi^{*}$ minima at $3.00 \mathrm{eV}\left(\left({ }^{3} \pi \pi^{*}\right)_{\min 2}\right)$ and $3.37 \mathrm{eV}\left(\left({ }^{3} \pi \pi^{*}\right)_{\min }\right)$ [46]. Nonadiabatic surface-hopping dynamic simulations including spin-orbit coupling suggest that the primary ISC pathway initiates from the $n \pi^{*}$ minimum of the $S_{1}$ state, initially populating the $T_{2} n \pi^{*}$ minimum and the $\left({ }^{3} \pi \pi^{*}\right)_{\min 2}$, which are isoenergetic [46,58]. Pathways from the $S_{1} \pi \pi^{*}$ minimum to the $T_{2}\left(n \pi^{*}\right)$ state, and from the $\mathrm{S}_{1} \mathrm{n} \pi^{*}$ minimum to $\left({ }^{3} \pi \pi^{*}\right)_{\min }$, are expected to be minor contributions to the overall ISC dynamics [58]. These calculations are consistent with our experimental results and suggest that we should assign $\tau_{1}$ to the combination of internal conversion from the $S_{2}$ state to the $S_{1}$ state, ISC from the $S_{1}$ state to the $\mathrm{T}_{2}$ state (or $\mathrm{T}_{1}$ state), and internal conversion from the $\mathrm{T}_{2}$ state to the $\mathrm{T}_{1}$ state.

The second lifetime $\left(\tau_{2}\right)$ observed in the ultrafast relaxation dynamics of $6 \mathrm{tGua}$ is more difficult to assign. During this timeframe, the spectral features are nearly identical to those observed for $6 \mathrm{tGuo}$, in which decay of the $520 \mathrm{~nm}$ band coincides with a rise of the $375 \mathrm{~nm}$ maximum [26]. For $6 \mathrm{tGuo}, \tau_{2}$ was assigned to a combination of solvation dynamics in the $\mathrm{T}_{1}\left(\pi \pi^{*}\right)$ state and internal conversion from the $S_{1}$ state to the ground state [26]. The latter was proposed due to apparent ground-state repopulation in the transient absorption data, which is also observed for $6 \mathrm{tGua}$ (Figure 5). Just as for $\tau_{1}$, this may be due to a rise in excited-state absorption on top of the ground-state depopulation signal (Figure 5). However, this is unlikely because the $375 \mathrm{~nm}$ maximum only increases in magnitude by $\sim 0.5 \mathrm{mOD}$, while the depopulated region increases by $\sim 3 \mathrm{mOD}$, suggesting that the ground-state repopulation process is mostly independent of overlapping absorption bands. This assignment is supported by MS-CASPT2/ /SA-CASSCF calculations, which predict an energetically-accessible $(\Delta \mathrm{E}=0.04 \mathrm{eV})$ conical intersection between the $S_{1} \pi \pi^{*}$ minimum and the ground-state PES [46,58]. Nonadiabatic surface-hopping dynamics excluding spin-orbit coupling (i.e., only singlet dynamics) predict that internal conversion from the $S_{1}$ state to the ground state would last for tens of picoseconds [58], which agrees with the time constant $\left(\tau_{2}\right)$ obtained from global analysis of the transient absorption data. These calculations support the assignment of $\tau_{2}$ to internal conversion from the $S_{1}$ state to the ground state, but they cannot explain the rise in magnitude of the transient absorption band centered at $375 \mathrm{~nm}$. For $6 \mathrm{tGuo}, \tau_{2}$ was shown to decrease significantly from $80 \pm 15$ to $32 \pm 5$ ps in going from PBS to acetonitrile, which is consistent with the assignment of solvent dynamics in the $\mathrm{T}_{1}\left(\pi \pi^{*}\right)$ state on an equal time scale. Therefore, we suggest that $\tau_{2}$ in $6 \mathrm{tGua}$ corresponds to a combination of internal conversion from the $S_{1}$ state to the ground state and solvent dynamics in the $T_{1}\left(\pi \pi^{*}\right)$ state, as suggested previously for 6tGuo [26], but further work is warranted. From the amplitudes of the bleaching signals before and after $\tau_{2}$, and taking into consideration the rise in absorption of the $375 \mathrm{~m}$ band, we estimate an upper limit of $25 \%$ for internal conversion to the ground sate. We stress that this is simply an estimation, not a quantitative yield.

\subsection{Effects of N9-Glycosylation on the Photophysics of $6 t \mathrm{Gua}$}

While the transient absorption spectral evolution of $6 \mathrm{tGua}$ and $6 \mathrm{tGuo}$ are nearly identical in aqueous solution, they exhibit significantly different excited-state kinetics. For each, $\tau_{1}$ was assigned primarily to the population of the lowest-energy triplet state, but this process is shown to occur nearly twice as fast in 6tGuo (Table 2). An increase in the rate of ISC upon N1-glycosylation of 2-thiothymine has been reported previously [28]. However, the opposite trend is observed for $\tau_{2}$, which seems to correspond to a combination of internal conversion from the $S_{1}$ state to the ground state and solvent dynamics in the $\mathrm{T}_{1}$ state. These differences suggest that N9-glycosylation of $6 \mathrm{tGua}$ enhances intersystem crossing from the singlet to triplet manifold, consequently making ground-state repopulation from the $S_{1}$ state less competitive. However, a comparison of the TD-DFT vertical 
excitation energies, computed with and without N9-glycosylation (Table 1), indicates that the sugar moiety has only a minor impact on the electronic structure of $6 \mathrm{tGua}$ at this level of theory [26]. Most notably, the $S_{1} / T_{2}$ and $S_{1} / T_{1}$ energy gaps remain $0.22 \mathrm{eV}$ and $0.90 \mathrm{eV}$ for $6 \mathrm{tGuo}$ in water, nearly identical to those reported for $6 \mathrm{tGua}$ in Table 1 . Therefore, the increase in the rates of intersystem crossing is proposed to be due to an increase in the density of vibrational states in the $S_{1}\left(n \pi^{*}\right), T_{2}\left(n \pi^{*}\right)$, and $\mathrm{T}_{1}\left(\pi \pi^{*}\right)$ states upon $\mathrm{N} 9$-glycosylation, allowing for more effective vibronic coupling between the singlet and triplet manifolds.

The most notable differences between $6 \mathrm{tGua}$ and $6 \mathrm{tGuo}$ dynamics are observed at the nano- and microsecond timescales (Figure 6). The triplet state of 6tGua intersystem crosses to the ground state with a 2-fold longer lifetime than $6 \mathrm{tGuo}$ using identical concentrations $(0.2 \mathrm{mM})$ under deaerated conditions [26]. This increase in the magnitude of the triplet-state lifetime has major consequences on excited-state reactivity, as $6 \mathrm{tGuo}$ shows a marked decrease in the ${ }^{1} \mathrm{O}_{2}$ quantum yield in going from $\mathrm{O}_{2}$ - to air-saturated aqueous solutions, while that for $6 \mathrm{tGua}$ remains constant within the error. A similar decrease in triplet-state lifetime was observed for 2-thiothymine upon N1-glycosylation in deaerated acetonitrile [27], and it was suggested that the increased density of vibrational modes from the deoxyribose group enhances coupling between the $T_{1}$ state and the ground state. At this time, a similar argument can be suggested to explain the enhanced rate of triplet decay for $6 \mathrm{tGua}$ upon N9-glycosylation. Further investigation is needed to scrutinize whether this is a general phenomenon observed in other sulfur-substituted nucleobases.

\section{Materials and Methods}

\subsection{Chemicals}

2-Amino-6-mercaptopurine (6tGua, 97\%) was obtained from Sigma Aldrich (St. Louis, MO, USA) and used as received. Solutions of $6 \mathrm{tGua}$ were prepared in aqueous phosphate buffer saline (PBS) at $\mathrm{pH}$ 7.4. PBS was prepared using $0.480 \mathrm{~g}$ of sodium dihydrogen phosphate and $0.354 \mathrm{~g}$ of disodium hydrogen phosphate dissolved in $400 \mathrm{~mL}$ of ultrapure water and adjusted to $\mathrm{pH} 7.4$ with concentrated sodium hydroxide.

\subsection{Steady-State Absorption and Emission Spectra}

Room-temperature absorption and emission spectra were recorded using a Cary Bio 100 spectrophotometer (Varian Inc., Palo Alto, CA, USA). Samples were prepared in cuvettes with $1 \mathrm{~cm}$ optical path length. Ground-state molar extinction coefficients were measured for 6tGua in PBS by making serial dilutions from a prepared stock solution.

\subsection{Steady-State and Time-Resolved Emission Spectra}

Steady-state and time-resolved luminescence spectra at $77 \mathrm{~K}$ were recorded on a Fluorolog-3 fluorimeter (HORIBA Jobin Yvon, Edison, NJ, USA) using $3 \mathrm{~mm}$ (inner diameter) quartz tubes inside a quartz liquid nitrogen dewar. The phosphorescence lifetime at $77 \mathrm{~K}$ was measured by multichannel scaling on an OB920 spectrometer (Edinburgh Analytical Instruments, Livingston, UK) in conjunction with a pulsed Xe-lamp.

Room-temperature emission spectra were obtained using a Cary Eclipse spectrofluorimeter (Varian, Inc.). Samples were prepared in cuvettes with $1 \mathrm{~cm}$ optical path length. Ground-state molar extinction coefficients were measured for $6 \mathrm{tGua}$ in PBS by making serial dilutions from a prepared stock solution. Emission spectra were measured at room temperature using an excitation wavelength of $340 \mathrm{~nm}$ under air- and $\mathrm{N}_{2}$-saturated conditions. Samples were purged for at least $30 \mathrm{~min}$ in septum-top cuvettes prior to data collection. Excitation spectra were recorded at each of the emission maxima under air-saturated conditions. Both the emission and excitation spectra were collected at a scan rate of $20 \mathrm{~nm} / \mathrm{min}$ with the excitation and emission slit widths set to $5 \mathrm{~nm}$ and the photomultiplier tube gain set to $800 \mathrm{~V}$. 


\subsection{Time-Dependent Density Functional Theory Calculations}

Quantum-chemical calculations were performed using the Gaussian 09 suite of programs [60]. Ground-state optimizations were performed for 6 tGua at the PBE0/IEFPCM/6-311++G(d,p) level of theory in vacuum, and water [61-63]. Vertical excitation energies were calculated using the optimized ground-state geometries with the TD-PBE0/IEFPCM/6-311++G(d,p) level of theory [64]. The adiabatic triplet energy was estimated from the difference in energy between the optimized triplet and the optimized ground-state geometries. Optimized triplet geometries was calculated at the UPBE0/IEFPCM/6-311++G(d,p) level of theory. The excited-state character was estimated from visual inspection of the Kohn-Sham orbitals and oscillator strengths. The percentage of single-electron contribution ( $\mathrm{y} \%$ ) to the vertical excitation energies was calculated using the following expression as done previously for TD-DFT calculations: [65,66]:

$$
y \%=\frac{x_{i}^{2}}{\sum_{i=1}^{n} x_{i}^{2}} \times 100
$$

where $x_{i}=$ single-electron transition.

TD-DFT calculations have been shown to satisfactorily model the electronic structure of the DNA nucleobases and nucleosides and their thio-derivatives [26,67-70]. Bulk solvent dielectric effects on the ground-state geometries and on the excited-state vertical excitations were modeled by including self-consistent reaction field (SCRF) calculations using the polarizable continuum model (PCM) with the integral equation formalism $($ SCRF = IEFPCM) [71]. The estimated error for the calculation of vertical excitation energies using this methodology is between $0.1 \mathrm{eV}$ to $0.3 \mathrm{eV}$ [67], justifying the shift in the vertical excitation energies by $0.15 \mathrm{eV}$ in Figure 2.

\subsection{Transient Absorption Spectroscopy}

Femtosecond broadband transient absorption spectroscopy was employed to study the excited-state dynamics of 6tGua. The laser and spectrometer setup is described in significant detail in previous publications [72,73]. In brief, a Ti:Sapphire oscillator (Vitesse, Coherent, Santa Clara, CA, USA) seeds a chirped pulse regenerative amplifier (Coherent Libra-HE). The amplifier generates $4 \mathrm{~mJ}$, $100 \mathrm{fs}$ pulses at $800 \mathrm{~nm}$ with a $1 \mathrm{kHz}$ repetition rate, which are used to pump an optical parametric amplifier (OPA, TOPAS, Quantronix/Light Conversion, Vilnius, Lithuania). A small fraction of the pump beam is split off prior to the OPA and focused through a constantly-moving $3 \mathrm{~mm} \mathrm{CaF}_{2} \mathrm{crystal}$ to generate a broadband probe pulse $(320 \mathrm{~nm}-710 \mathrm{~nm})$. For each molecule, the OPA was tuned to excitation wavelength of $345 \mathrm{~nm}$. Excitation pulses were set to an intensity of $1 \mu \mathrm{J}$ at the sample using a neutral density optical filter in order to minimize cross-phase modulation effects as well as sample degradation [65]. The setup employs a mechanical delay stage to adjust the time it takes the probe pulse to reach the sample up to a maximum delay of $3 \mathrm{~ns}$. The broadband probe pulses are split into two fractions. One beam passes through the sample ( $2 \mathrm{~mm}$ path length) to probe the transient signals, while the other serves to correct for changes in the white light continuum throughout the experiment. The pulses are focused into optical fibers leading to CMOS detection units. Generation of the reference signal comes via a chopper wheel, which blocks every other pump pulse, providing an alternating sequence of spectra with and without sample excitation, and thus providing $\Delta \mathrm{A}$ transient absorption data. In order to observe dynamics at longer than the 3 ns capability of our mechanical delay stage, an electronically-triggered white light source (Eos, Ultrafast Systems, LLC, Sarasota, FL, USA) is used to generate a probe pulse with a spectral window from $\sim 375 \mathrm{~nm}$ to $800 \mathrm{~nm}$, a time resolution of $400 \mathrm{ps,}$ and a temporal window of up to $120 \mu$ s [72,73]. During the experiments, solutions were continuously stirred using a Teflon stir bar. Samples were prepared at a ground-state absorption of $\sim 0.5$ OD (0.2 mM in PBS) at the excitation wavelength for all experiments, unless stated otherwise. When using the Eos white light source, 6tGua was studied in both air- and $\mathrm{N}_{2}$-saturated solutions. $\mathrm{N}_{2}$-saturated solutions were purged for $30 \mathrm{~min}$ prior and blanketed with $\mathrm{N}_{2}$ for the course of the experiment. Degradation of 
6tGua was monitored at $340 \mathrm{~nm}$ in PBS. Samples were replaced with fresh solutions before the change in absorbance reached $5 \%$.

A homemade software (Labview, National Instruments, Inc., Austin, TX, USA) was used for data collection. Prior to analysis, the data was corrected for group velocity dispersion of the probe pulse using the two-photon absorption signal of neat methanol. Approximately 80 kinetic traces were extracted from the multidimensional transient absorption data for global and target analysis with Igor Pro 6.36 [74]. Traces for 6tGua were globally fit to a two-lifetime exponential model [75]. The instrument response function was held at $200 \mathrm{fs}$ in all cases, as determined from the two-photon coherent signal from neat methanol (IRF of $200 \pm 50 \mathrm{fs}$ ) [76]. The nanosecond decay dynamics of 6tGua were collected using the Eos white light source and 30 kinetic traces were extracted from each data set and globally fit to a single-exponential kinetic model.

\subsection{Determination of Singlet Oxygen Yields}

Nanosecond time-resolved luminescence spectroscopy was employed to determine the quantum yield of ${ }^{1} \mathrm{O}_{2}$ produced by 6tGua following UVA excitation [19,28,54]. Briefly, a GCR-150-30 Nd:YAG laser (Spectra Physics, Santa Clara, CA, USA, $355 \mathrm{~nm}, 7 \mathrm{~ns}$ pulse width) was used as the excitation source. ${ }^{1} \mathrm{O}_{2}$ phosphorescent decay traces were collected at $1270 \mathrm{~nm}$ using a modified Fluorolog-3 spectrometer (HORIBA, Jobin Yvon) with a NIR sensitive photomultiplier tube (H102330A-45, Hamamatsu, Hamamatsu City, Japan). The decay traces were then stored on a digital oscilloscope (TDS 360, Tektronics, Beaverton, OR, USA). Solutions of 6tGua and the phenalenone standard were prepared in Tris-buffered $\mathrm{D}_{2} \mathrm{O}$ at an optical density of 0.3 at $355 \mathrm{~nm}$ in $1 \mathrm{~cm}$ path length quartz cuvettes. The $\mathrm{O}_{2}$-saturated solutions were bubbled with ultrapure oxygen gas for $>20 \mathrm{~min}$ prior to testing. Degradation of the samples was determined to be less than $3 \%$ over the course of the experiments based on their steady-state absorption spectra. The quantum yields were determined in back-to-back luminescence experiments of $6 \mathrm{tGua}$ and phenalenone solutions under identical conditions, using the reported yield of ${ }^{1} \mathrm{O}_{2}$ generated by phenalenone $\left(\Phi_{\Delta}=0.98\right)$ [52].

\section{Conclusions}

The excited-state dynamics of $6 \mathrm{tGua}$ have been studied from femtosecond to microsecond time-delays following UVA excitation under physiological conditions. TD-DFT computations and previous high-level quantum-chemical calculations for 6tGua were used to assist in the assignment of the relaxation pathways. We show that $6 \mathrm{tGua}$ populates the triplet manifold within $\sim 600 \mathrm{fs}$ followed by decay of the excited-state population from the lowest-energy triplet state to the ground-state in 1.4 and $0.8 \mu \mathrm{s}$ in deaerated and in air-saturated aqueous solution, respectively. Upon UVA excitation, 6tGua produces ${ }^{1} \mathrm{O}_{2}$ with quantum yields of 0.21 (air) and $0.23\left(\mathrm{O}_{2}\right)$ in PBS, indicating that the nucleobase has the potential to act as Type II photosensitizer before metabolization in the cell cytoplasm. These yields are in good agreement with those reported recently for 6tGuo [19], but approximately twofold less than those previously reported by Gao et al. for 6tGua [9]. They are also twice as small as those reported recently for mono- and di-sulfur substituted pyrimidine bases under equal experimental conditions $[28,54]$.

To provide insight into the effects of N9-glycosylation on the excited-state dynamics of $6 \mathrm{tGua}$, we compared our results with those previously reported for $6 \mathrm{tGuo}$ under similar conditions. Notably, $6 \mathrm{tGuo}$ populates the triplet manifold nearly twice as fast as 6tGua following UVA excitation. The same effect was recently reported for 2tThy, in which N1-glycosylation decreases the magnitude of the ISC lifetime by $\sim 200 \mathrm{fs}$ [28]. Additionally, intersystem crossing from the lowest-energy triplet-state to the ground state occurs nearly twice as fast for $6 \mathrm{tGuo}$ in deaerated aqueous solution. A comparison of TD-DFT calculations including solvent effects indicates that N9-glycoslyation should have minimal effects on the electronic structure of 6tGua [26]. However, an increased density of vibrational modes expected upon glycosylation could enhance vibronic coupling between the singlet and triplet manifolds. This can explain the increased rate of ISC observed for $6 \mathrm{tGua}$ following glycosylation, 
and is supported by a recent comparison of 2-thiothymine and 2-thiothymidine in acetonitrile, in which 2-thiothymidine exhibited a significantly shorter triplet lifetime [27]. Therefore, the results presented in this work contribute significantly to understanding and generalizing the role of glycosylation on the photochemical properties of these prodrugs, as well as on other thiobase derivatives.

Supplementary Materials: The following are available online. Figure S1: (a) Emission spectra of 6tGua in PBS with an excitation wavelength of $340 \mathrm{~nm}$ under air- and N2-saturated conditions. (b) Excitation spectra at the $420 \mathrm{~nm}$ and $480 \mathrm{~nm}$ emission maxima is plotted with the ground-state absorption spectrum of 6tGua, Figure S2: Kohn-Sham orbitals of 6tGua associated with the single-electron transitions of relevant excited-states with energies equal or less than the $345 \mathrm{~nm}$ excitation used in this work.

Acknowledgments: The authors acknowledge funding from the CAREER program of the National Science Foundation (Grants No. CHE-1255084 and CHE-1539808). The authors also thank Glesmarie Ortiz-Zayas for collecting some of the nanosecond transient absorption data reported in this work for $6 \mathrm{tGua}$.

Author Contributions: C.E.C.-H. conceived and designed the experiments; B.A. and S.J. performed the experiments; B.A. and S.J. analyzed the data; C.E.C.-H. and S.J. contributed reagents/materials/analysis tools; B.A. and C.E.C.-H. wrote the paper.

Conflicts of Interest: The authors declare no conflict of interest.

\section{References}

1. Swann, P.F.; Waters, T.R.; Moulton, D.C.; Xu, Y.-Z. Role of postreplicative DNA mismatch repair in the cytotoxic action of thioguanine. Science 1996, 273, 1109-1111. [CrossRef] [PubMed]

2. Flowers, C.R.; Melmon, K.L. Clinical investigators as critical determinants in pharmaceutical innovation. Nat. Med. 1997, 3, 136-143. [CrossRef] [PubMed]

3. Bernstein, C.N.; Blanchard, J.F.; Kliewer, E.; Wajda, A. Cancer risk in patients with inflammatory bowel disease. Cancer 2001, 91, 854-862. [CrossRef]

4. Weinshilboum, R. Thiopurine pharmacogenetics: Clinical and molecular studies of thiopurine methyltransferase. Drug Metab. Dispos. 2001, 29, 601-605. [PubMed]

5. Euvrard, S.; Kanitakis, J.; Claudy, A. Skin cancers after organ transplantation. N. Engl. J. Med. 2003, 348, 1681-1691. [CrossRef] [PubMed]

6. Sahasranaman, S.; Howard, D.; Roy, S. Clinical pharmacology and pharmacogenetics of thiopurines. Eur. J. Clin. Pharmacol. 2008, 64, 753-767. [CrossRef] [PubMed]

7. Warren, D.J.; Andersen, A.; Slørdal, L. Quantitation of 6-thioguanine residues in peripheral blood leukocyte DNA obtained from patients receiving 6-mercaptopurine-based maintenance therapy. Cancer Res. 1995, 55, 1670-1674. [PubMed]

8. Cuffari, C.; Seidman, E.; Latour, S.; Theoret, Y. Quantitation of 6-thioguanine in peripheral blood leukocyte DNA in crohn's disease patients on maintenance 6-mercaptopurine therapy. Can. J. Physiol. Pharmacol. 1996, 74, 580-585. [CrossRef] [PubMed]

9. Zhang, Y.; Zhu, X.; Smith, J.; Haygood, M.T.; Gao, R. Direct observation and quantitative characterization of singlet oxygen in aqueous solution upon UVA excitation of 6-thioguanines. J. Phys. Chem. B 2011, 115, 1889-1894. [CrossRef] [PubMed]

10. Brem, R.; Guven, M.; Karran, P. Oxidatively-generated damage to DNA and proteins mediated by photosensitized UVA. Free Radic. Biol. Med. 2016. [CrossRef] [PubMed]

11. Cooke, M.S.; Duarte, T.L.; Cooper, D.; Chen, J.; Nandagopal, S.; Evans, M.D. Combination of azathioprine and UVA irradiation is a major source of cellular 8-oxo-7, 8-dihydro-2'-deoxyguanosine. DNA Repair 2008, 7, 1982-1989. [CrossRef] [PubMed]

12. Karran, P.; Attard, N. Thiopurines in current medical practice: Molecular mechanisms and contributions to therapy-related cancer. Nat. Rev. Cancer 2008, 8, 24-36. [CrossRef] [PubMed]

13. Brem, R.; Karran, P. Multiple forms of DNA damage caused by UVA photoactivation of DNA 6-thioguanine. Photochem. Photobiol. 2012, 88, 5-13. [CrossRef] [PubMed]

14. Karran, P. Thiopurines, DNA damage, DNA repair and therapy-related cancer. Br. Med. Bull. 2006, 79, 153-170. [CrossRef] [PubMed] 
15. Zhang, X.; Jeffs, G.; Ren, X.; O’Donovan, P.; Montaner, B.; Perrett, C.M.; Karran, P.; Xu, Y.-Z. Novel DNA lesions generated by the interaction between therapeutic thiopurines and UVA light. DNA Repair 2007, 6, 344-354. [CrossRef] [PubMed]

16. Ren, X.; Li, F.; Jeffs, G.; Zhang, X.; Xu, Y.-Z.; Karran, P. Guanine sulphinate is a major stable product of photochemical oxidation of DNA 6-thioguanine by UVA irradiation. Nucleic Acids Res. 2010, 38, 1832-1840. [CrossRef] [PubMed]

17. Gueranger, Q.; Kia, A.; Frith, D.; Karran, P. Crosslinking of DNA repair and replication proteins to DNA in cells treated with 6-thioguanine and UVA. Nucleic Acids Res. 2011, 39, 5057-5066. [CrossRef] [PubMed]

18. Zhang, Y.; Barnes, A.N.; Zhu, X.; Campbell, N.F.; Gao, R. Quantification of thiopurine/UVA-induced singlet oxygen production. J. Photochem. Photobiol. A 2011, 224, 16-24. [CrossRef] [PubMed]

19. Pollum, M.; Ortiz-Rodríguez, L.A.; Jockusch, S.; Crespo-Hernández, C.E. The triplet state of 6-thio-2'-deoxyguanosine: Intrinsic properties and reactivity toward molecular oxygen. Photochem. Photobiol. 2016, 92, 286-292. [CrossRef] [PubMed]

20. Bishop, S.M.; Malone, M.; Phillips, D.; Parker, A.W.; Symons, M.C. Singlet oxygen sensitisation by excited state DNA. J. Chem. Soc. Chem. Commun. 1994, 871-872. [CrossRef]

21. Hemmens, V.J.; Moore, D.E. Photo-oxidation of 6-mercaptopurine in aqueous solution. J. Chem. Soc. Perkin Trans. II 1984, 209-211. [CrossRef]

22. Hemmens, V.J.; Moore, D.E. Photochemical sensitization by azathioprine and its metabolites-I. 6-mercaptopurine. Photochem. Photobiol. 1986, 43, 247-255. [CrossRef] [PubMed]

23. Wenska, G.; Filipiak, P.; Taras-Goślińska, K.; Sobierajska, A.; Gdaniec, Z. Orientation-dependent quenching of the triplet excited 6-thiopurine by nucleobases. J. Photochem. Photobiol. A 2011, 217, 55-61. [CrossRef]

24. Brem, R.; Daehn, I.; Karran, P. Efficient DNA interstrand crosslinking by 6-thioguanine and UVA radiation. DNA Repair 2011, 10, 869-876. [CrossRef] [PubMed]

25. Wang, Z.; Rana, T.M. RNA-protein interactions in the tat-trans-activation response element complex determined by site-specific photo-cross-linking. Biochemistry 1998, 37, 4235-4243. [CrossRef] [PubMed]

26. Reichardt, C.; Guo, C.; Crespo-Hernández, C.E. Excited-state dynamics in 6-thioguanosine from the femtosecond to microsecond time scale. J. Phys. Chem. B. 2011, 115, 3263-3270. [CrossRef] [PubMed]

27. Taras-Goślińska, K.; Burdziński, G.; Wenska, G. Relaxation of the $\mathrm{T}_{1}$ excited state of 2-thiothymine, its riboside and deoxyriboside-enhanced nonradiative decay rate induced by sugar substituent. J. Photochem. Photobiol. A 2014, 275, 89-95. [CrossRef]

28. Pollum, M.; Jockusch, S.; Crespo-Hernández, C.E. 2,4-dithiothymine as a potent UVA chemotherapeutic agent. J. Am. Chem. Soc. 2014, 136, 17930-17933. [CrossRef] [PubMed]

29. Zou, X.; Zhao, H.; Yu, Y.; Su, H. Formation of guanine-6-sulfonate from 6-thioguanine and singlet oxygen: A combined theoretical and experimental study. J. Am. Chem. Soc. 2013, 135, 4509-4515. [CrossRef] [PubMed]

30. Rubin, Y.V.; Blagoi, Y.P.; Bokovoy, V. 6-Thioguanine luminescence probe to study DNA and low-molecular-weight systems. J. Fluoresc. 1995, 5, 263-272. [CrossRef] [PubMed]

31. Rubin, Y.V. Physical properties of anticancer drug 6-thioguanine. In Proceedings of the SPIE 5507; International Society for Optics and Photonics: Bellingham, WA, USA, 2004; pp. 346-357.

32. Chuan, D.; Wen, Y.; Shaomin, S.; Pin, Y. Determination of thioguanine in pharmaceutical preparations by paper substrate room temperature phosphorimetry. Analyst 2000, 125, 1327-1330. [CrossRef] [PubMed]

33. Stewart, M.J.; Leszczynski, J.; Rubin, Y.V.; Blagoi, Y.P. Tautomerism of thioguanine: From gas phase to DNA. J. Phys. Chem. A 1997, 101, 4753-4760. [CrossRef]

34. Reichardt, C.; Crespo-Hernández, C.E. Room-temperature phosphorescence of the DNA monomer analogue 4-thiothymidine in aqueous solutions after UVA excitation. J. Phys. Chem. Lett. 2010, 1, 2239-2243. [CrossRef]

35. Vendrell-Criado, V.; Sáez, J.A.; Lhiaubet-Vallet, V.; Cuquerella, M.C.; Miranda, M.A. Photophysical properties of 5-substituted 2-thiopyrimidines. Photochem. Photobiol. Sci. 2013, 12, 1460-1465. [CrossRef] [PubMed]

36. Kuramochi, H.; Kobayashi, T.; Suzuki, T.; Ichimura, T. Excited-state dynamics of 6-aza-2-thiothymine and 2-thiothymine: Highly efficient intersystem crossing and singlet oxygen photosensitization. J. Phys. Chem. B 2010, 114, 8782-8789. [CrossRef] [PubMed]

37. Harada, Y.; Suzuki, T.; Ichimura, T.; Xu, Y.-Z. Triplet formation of 4-thiothymidine and its photosensitization to oxygen studied by time-resolved thermal lensing technique. J. Phys. Chem. B 2007, 111, 5518-5524. [CrossRef] [PubMed] 
38. Lancelot, G.; Helene, C. Spin-orbit coupling in sulphur-containing purine and pyrimidine derivatives. A comparison of caffeine and 6-thiocaffeine. Chem. Phys. Lett. 1971, 9, 327-331. [CrossRef]

39. Lim, E.; Li, Y.; Li, R. Vibronic interactions between $\mathrm{n} \pi^{*}$ and $\pi \pi^{*}$ states and radiative and nonradiative $\mathrm{T}_{1} \rightarrow \mathrm{S}_{0}$ transitions in aromatic carbonyl compounds. J. Chem. Phys. 1970, 53, 2443-2448. [CrossRef]

40. Shain, A.L.; Sharnoff, M. Static and dynamic paramagnetism of the undistorted triplet state of benzophenone. J. Chem. Phys. 1973, 59, 2335-2343. [CrossRef]

41. Taherian, M.-R.; Maki, A. Optically detected magnetic resonance study of the phosphorescent states of thiouracils. Chem. Phys. 1981, 55, 85-96. [CrossRef]

42. Wenska, G.; Taras-Goślińska, K.; Łukaszewicz, A.; Burdziński, G.; Koput, J.; Maciejewski, A. Mechanism and dynamics of intramolecular triplet state decay of 1-propyl-4-thiouracil and its $\alpha$-methyl-substituted derivatives studied in perfluoro-1, 3-dimethylcyclohexane. Photochem. Photobiol. Sci. 2011, 10, 1294-1302. [CrossRef] [PubMed]

43. Martínez-Fernández, L.; Pepino, A.J.; Segarra-Martí, J.; Banyasz, A.; Garavelli, M.; Improta, R. Computing the absorption and emission spectra of 5-methylcytidine in different solvents: A test-case for different solvation models. J. Chem. Theory Comput. 2016, 12, 4430-4439. [CrossRef] [PubMed]

44. Mai, S.; Ashwood, B.; Pollum, M.; Marquetand, P.; Crespo-Hernández, C.E.; González, L. Solvatochromic effects on the absorption spectrum of 2-thiocytosine. J. Phys. Chem. 2017. submitted.

45. Martínez-Fernández, L.; Granucci, G.; Pollum, M.; Crespo-Hernández, C.; Persico, M.; Corral Perez, I. Decoding the molecular basis for the population mechanism of the triplet phototoxic precursors in UVA light-activated pyrimidine anticancer drugs. Chem. Eur. J. 2017, 23, 2619-2627. [CrossRef] [PubMed]

46. Martínez-Fernández, L.; González, L.; Corral, I. An ab initio mechanism for efficient population of triplet states in cytotoxic sulfur substituted DNA bases: The case of 6-thioguanine. Chem. Commun. 2012, 48, 2134-2136. [CrossRef] [PubMed]

47. Jacquemin, D.; Duchemin, I.; Blondel, A.; Blase, X. Benchmark of bethe-salpeter for triplet excited-states. J. Chem. Theory Comput. 2017, 13, 767-783. [CrossRef] [PubMed]

48. Silva-Junior, M.R.; Schreiber, M.; Sauer, S.P.; Thiel, W. Benchmarks for electronically excited states: Time-dependent density functional theory and density functional theory based multireference configuration interaction. J. Chem. Phys. 2008, 129, 104103. [CrossRef] [PubMed]

49. Mai, S.; Pollum, M.; Martínez-Fernández, L.; Dunn, N.; Marquetand, P.; Corral, I.; Crespo-Hernández, C.E.; González, L. The origin of efficient triplet state population in sulfur-substituted nucleobases. Nat. Commun. 2016, 7, 13077. [CrossRef] [PubMed]

50. Pollum, M.; Martínez-Fernández, L.; Crespo-Hernández, C.E. Photochemistry of nucleic acid bases and their thio-and aza-analogues in solution. In Photoinduced Phenomena in Nucleic Acids I; Springer: Berlin, Germany, 2015; Volume 355, pp. 245-327.

51. El-Sayed, M. Spin-Orbit coupling and the radiationless processes in nitrogen heterocyclics. J. Chem. Phys. 1963, 38, 2834-2838. [CrossRef]

52. Schmidt, R.; Tanielian, C.; Dunsbach, R.; Wolff, C. Phenalenone, a universal reference compound for the determination of quantum yields of singlet oxygen $\mathrm{O}_{2}\left({ }^{1} \Delta_{\mathrm{g}}\right)$ sensitization. J. Photochem. Photobiol. A 1994, 79, 11-17. [CrossRef]

53. Pollum, M.; Crespo-Hernández, C.E. Communication: The dark singlet state as a doorway state in the ultrafast and efficient intersystem crossing dynamics in 2-thiothymine and 2-thiouracil. J. Chem. Phys. 2014, 140, 071101. [CrossRef] [PubMed]

54. Pollum, M.; Jockusch, S.; Crespo-Hernández, C.E. Increase in the photoreactivity of uracil derivatives by doubling thionation. Phys. Chem. Chem. Phys. 2015, 17, 27851-27861. [CrossRef] [PubMed]

55. Harada, Y.; Okabe, C.; Kobayashi, T.; Suzuki, T.; Ichimura, T.; Nishi, N.; Xu, Y.-Z. Ultrafast intersystem crossing of 4-thiothymidine in aqueous solution. J. Phys. Chem. Lett. 2009, 1, 480-484. [CrossRef]

56. Bai, S.; Barbatti, M. Why replacing different oxygens of thymine with sulfur causes distinct absorption and intersystem crossing. J. Phys. Chem. A 2016, 120, 6342-6350. [CrossRef] [PubMed]

57. Gao, X.; Bai, S.; Fazzi, D.; Niehaus, T.; Barbatti, M.; Thiel, W. Evaluation of spin-orbit couplings with linear-response TD-DFT, TDA, and TD-DFTB. J. Chem. Theory Comput. 2017, 13, 515-524. [CrossRef] [PubMed] 
58. Martínez-Fernández, L.; Corral, I.; Granucci, G.; Persico, M. Competing ultrafast intersystem crossing and internal conversion: A time resolved picture for the deactivation of 6-thioguanine. Chem. Sci. 2014, 5, 1336-1347. [CrossRef]

59. Mai, S.; Marquetand, P.; González, L. Intersystem crossing pathways in the noncanonical nucleobase 2-thiouracil: A time-dependent picture. J. Phys. Chem. Lett. 2016, 7, 1978-1983. [CrossRef] [PubMed]

60. Frisch, M.J.; Trucks, G.W.; Schlegel, H.B.; Scuseria, G.E.; Robb, M.A.; Cheeseman, J.R.; Scalmani, G.; Barone, V.; Petersson, G.A.; Nakatsuji, H.; et al. Gaussian 09; Gaussian, Inc.: Wallingford, CT, USA, 2009.

61. Lee, C.; Yang, W.; Parr, R.G. Development of the colle-salvetti correlation-energy formula into a functional of the electron density. Phys. Rev. B 1988, 37, 785. [CrossRef]

62. Becke, A.D. A new mixing of hartree-fock and local density-functional theories. J. Chem. Phys. 1993, 98, 1372-1377. [CrossRef]

63. Becke, A.D. Density-functional thermochemistry. III. The role of exact exchange. J. Chem. Phys. 1993, 98, 5648-5652. [CrossRef]

64. Adamo, C.; Barone, V. Toward reliable density functional methods without adjustable parameters: The PBE0 model. J. Chem. Phys. 1999, 110, 6158-6170. [CrossRef]

65. Vogt, R.A.; Gray, T.G.; Crespo-Hernández, C.E. Subpicosecond intersystem crossing in mono-and di (organophosphine) gold (I) naphthalene derivatives in solution. J. Am. Chem. Soc. 2012, 134, 14808-14817. [CrossRef] [PubMed]

66. Brister, M.M.; Piñero-Santiago, L.E.; Morel, M.; Arce, R.; Crespo-Hernández, C.E. The photochemical branching ratio in 1,6-dinitropyrene depends on the excitation energy. J. Phys. Chem. Lett. 2016, 7, 5086-5092. [CrossRef] [PubMed]

67. Jacquemin, D.; Mennucci, B.; Adamo, C. Excited-state calculations with TD-DFT: From benchmarks to simulations in complex environments. Phys. Chem. Chem. Phys. 2011, 13, 16987-16998. [CrossRef] [PubMed]

68. Improta, R.; Barone, V. Absorption and fluorescence spectra of uracil in the gas phase and in aqueous solution: A TD-DFT quantum mechanical study. J. Am. Chem. Soc. 2004, 126, 14320-14321. [CrossRef] [PubMed]

69. Shukla, M.; Leszczynski, J. Electronic transitions of thiouracils in the gas phase and in solutions: Time-dependent density functional theory (TD-DFT) study. J. Phys. Chem. A. 2004, 108, 10367-10375. [CrossRef]

70. Varsano, D.; Di Felice, R.; Marques, M.A.; Rubio, A. A TD-DFT study of the excited states of DNA bases and their assemblies. J. Phys. Chem. B. 2006, 110, 7129-7138. [CrossRef] [PubMed]

71. Cances, E.; Mennucci, B.; Tomasi, J. A new integral equation formalism for the polarizable continuum model: Theoretical background and applications to isotropic and anisotropic dielectrics. J. Chem. Phys. 1997, 107, 3032-3041. [CrossRef]

72. Reichardt, C.; Vogt, R.A.; Crespo-Hernández, C.E. On the origin of ultrafast nonradiative transitions in nitro-polycyclic aromatic hydrocarbons: Excited-state dynamics in 1-nitronaphthalene. J. Chem. Phys. 2009, 131, 224518. [CrossRef] [PubMed]

73. Reichardt, C.; Wen, C.; Vogt, R.A.; Crespo-Hernández, C.E. Role of intersystem crossing in the fluorescence quenching of 2-aminopurine 2'-deoxyriboside in solution. Photochem. Photobiol. Sci. 2013, 12, 1341-1350. [CrossRef] [PubMed]

74. Capellos, C.; Bielski, B.H. Mathematical Description of Chemical Kinetics in Solution Kinetic Systems; Wiley Interscience: New York, NY, USA, 1972.

75. Van Stokkum, I.H.; Larsen, D.S.; van Grondelle, R. Global and target analysis of time-resolved spectra. Biochim. Biophys. Acta 2004, 1657, 82-104. [CrossRef] [PubMed]

76. Rasmusson, M.; Tarnovsky, A.N.; Åkesson, E.; Sundström, V. On the use of two-photon absorption for determination of femtosecond pump-probe cross-correlation functions. Chem. Phys. Lett. 2001, 335, 201-208. [CrossRef]

Sample Availability: Sample Availability: Samples of the compounds are not available from the authors.

(C) 2017 by the authors. Licensee MDPI, Basel, Switzerland. This article is an open access article distributed under the terms and conditions of the Creative Commons Attribution (CC BY) license (http:/ / creativecommons.org/licenses/by/4.0/). 